This item was submitted to Loughborough's Research Repository by the author.

Items in Figshare are protected by copyright, with all rights reserved, unless otherwise indicated.

\title{
Motivational climate interventions in physical education: a meta-analysis
}

PLEASE CITE THE PUBLISHED VERSION

http://dx.doi.org/10.1016/j.psychsport.2011.06.005

\section{PUBLISHER}

(c) Elsevier Ltd

\section{VERSION}

AM (Accepted Manuscript)

\section{LICENCE}

CC BY-NC-ND 4.0

\section{REPOSITORY RECORD}

Braithwaite, Rock, Christopher M. Spray, and Victoria E. Warburton. 2019. "Motivational Climate Interventions in Physical Education: A Meta-analysis". figshare. https://hdl.handle.net/2134/11345. 
This item was submitted to Loughborough's Institutional Repository (https://dspace.lboro.ac.uk/) by the author and is made available under the following Creative Commons Licence conditions.

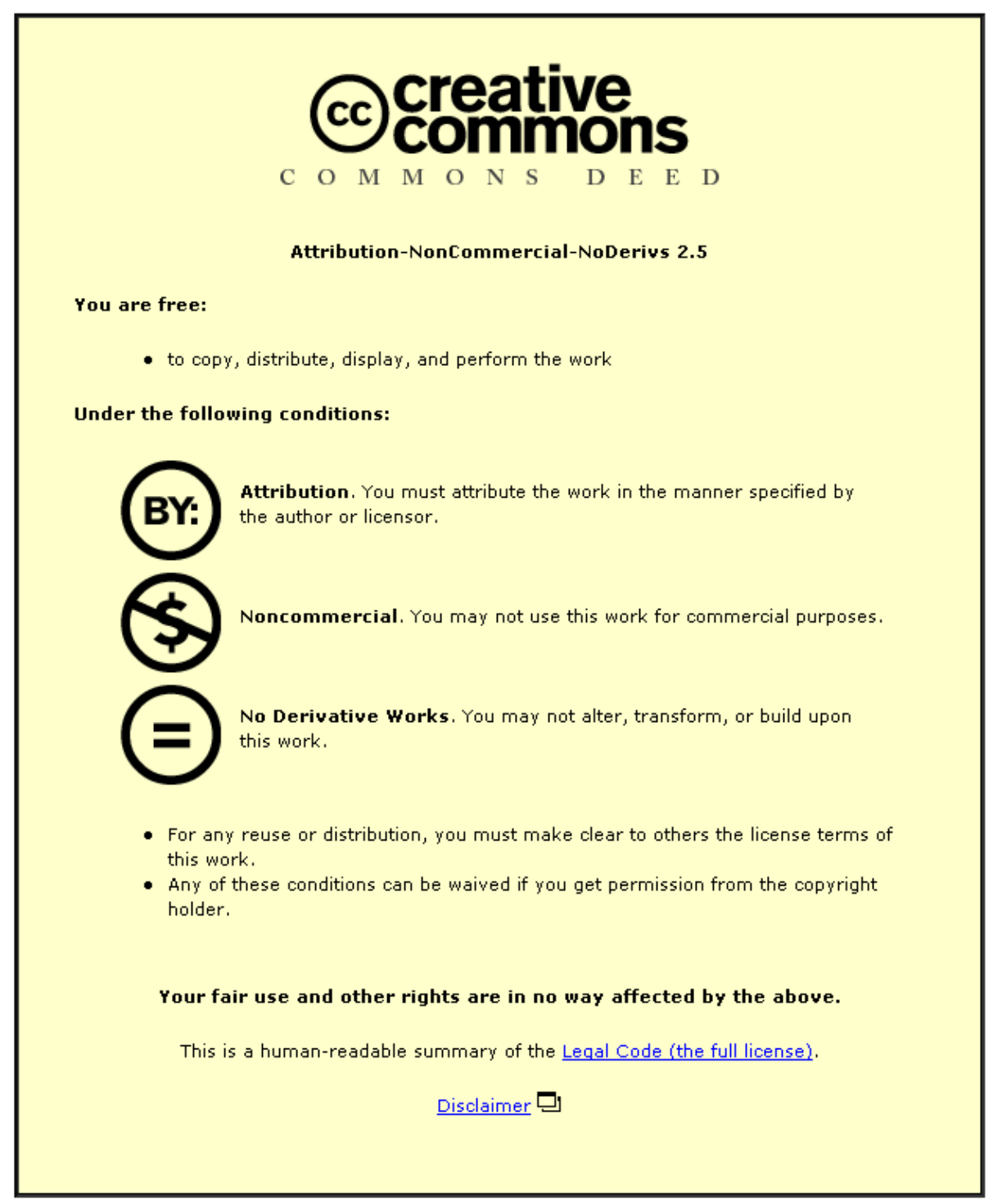

For the full text of this licence, please go to: http://creativecommons.org/licenses/by-nc-nd/2.5/ 


\section{Running Head: MOTIVATIONAL CLIMATE INTERVENTIONS}

2

3

4

5

6

Motivational Climate Interventions in Physical Education: A Meta-Analysis

7

8

9

10

11

12

13 Date submitted: February 24, 2011

14 Date resubmitted: May 29, 2011

15 Date Resubmitted: June 16, 2011

16

17 


\section{Abstract}

\section{Objective}

6 Design

The present study employed a quantitative research synthesis design. Meta-analysis uses

8 empirical studies to summarise past research by drawing overall conclusions from separate

9 investigations. This research design highlights important and unsolved issues related to

10 motivational climate interventions within physical education.

\section{Methods}

12 Standard meta-analytic procedures incorporating inclusion and exclusion criteria,

13 literature search, coding procedures, and statistical methods were used to identify and synthesise 1422 studies with 24 independent samples. Cohen's (1988) criteria for effect sizes were used to 15 interpret and evaluate results.

\section{Results}

17 There was an overall small positive treatment effect $(g=0.103)$ for groups exposed to 18 mastery motivational climates. Outcome analyses identified the most consistent and largest

19 overall treatment effects for behavioural outcomes $(g=0.39$ to 0.49$)$ followed by affective 20 outcomes $(g=-0.27$ to 0.59$)$ and cognitive outcomes $(g=-0.25$ to 0.32$)$. Moderator analyses

21 were directed by study heterogeneity and identified several trends in intervention features and

22 study features with the most substantial trend for participant features as elementary students had 23 the largest overall treatment effect $(g=0.41)$. 


\section{Conclusions}

2 Outcome and moderator analyses identified several trends in methodological features,

3 participant features, and study features that should be addressed in future physical education

4 motivational climate interventions.

\section{$5 \quad$ Keywords}




\section{Motivational Climate Interventions in Physical Education: A Meta-Analysis}

The study of motivational processes in achievement contexts has been evident in

3 psychological literature for many decades (Elliot \& Dweck, 2005). Prominent in this area of

4 inquiry is achievement goal theory (AGT; Ames, 1992a,b; Dweck, 1986, 1999; Elliot, 1999;

5 Nicholls, 1989). This approach places competence at the heart of achievement striving and

6 stresses that competence can be viewed by individuals in different ways. These differences arise

7 from individual and situational factors and lead to cognitive, affective and behavioral outcomes.

8 Although the roots of AGT lie in education, a significant body of work has examined key tenets

9 in physical activity settings, notably sport and school physical education (PE). This paper sets

10 out to synthesize the extant literature on the influence of situational factors in such settings.

11 Specifically, we aimed to quantitatively summarize the effects of motivational climate

12 interventions on specific outcomes, examine potential moderators of effects, and identify good

13 practice in future research into climate interventions.

\section{Motivational Climate}

15 Within AGT, the term 'motivational climate' has been adopted to encompass the study of

16 environmental factors that lead individuals to construe competence in different ways and pursue

17 different goals. One way to define one's competence is through the perception of self

18 improvement and mastery of skills, whereas a second perspective entails the comparison of one's

19 own ability with that of others in a salient reference group. Logically, individuals who employ

20 the first definition pursue goals centered on striving to improve and master tasks; on the other

21 hand, those individuals who choose to adopt the second definition pursue goals focused on doing

22 better than others (Nicholls, 1989). Although different frameworks and perspectives exist under

23 the broad umbrella term of AGT (Ames, 1992a, b; Elliot, 1999; Nicholls, 1989), all theorists 
1 agree that, in addition to or in combination with intrapsychic factors, goal adoption can be

2 determined by environmental features (i.e., the motivational climate).

3 Motivational climates in the physical domain that emphasize effort and personal

4 improvement have been termed task or mastery climates, whereas climates emphasizing

5 normative comparison and doing better than others have been referred to as ego or performance

6 climates (for reviews, see Duda \& Whitehead, 1998; Harwood, Spray \& Keegan, 2008). Drawing

7 from the classroom-based work of Ames (1992a), research in sport and PE has been particularly

8 concerned with identifying the motivational ramifications or correlates of perceived mastery and

9 performance climates. That is, it has been considered important to understand the consequences

10 of the situational goals held to be salient through the behaviors of key social agents. In PE and

11 sport, the key agents that have received the most research attention are teachers and coaches,

12 although some studies have examined parents and peers. These agents thus 'create' a

13 motivational climate based on the way they relate to sport and PE participants.

14 One means by which the specific behaviors of sports coaches and PE teachers can be

15 understood in terms of emphasizing the salience of particular goals is through the TARGET

16 framework (Ames, 1992a,b; Epstein, 1989). The acronym TARGET refers to Task (design of

17 activities), Authority (location of decision-making), Recognition (manner of distributing rewards

18 such as praise), Grouping (criteria for selecting working groups), Evaluation (standards of

19 performance considered important), and Time (pace of learning). A mastery climate is more

20 likely to be perceived when tasks are challenging, participants are provided with choices and

21 opportunities to exercise leadership, recognition is provided privately to individuals, participants

22 work in mixed ability groupings, positive evaluation for personal improvement is emphasized,

23 and variability in pace of learning is accommodated. A performance climate is more likely to be

24 reported by sports and PE participants when coaches and teachers organize repetitive and 
1 uniform tasks, control all aspects of decision-making, provide praise publicly, arrange groupings

2 reflective of rank order of ability, praise and reward only the more able in the class or team, and

3 do not allow slower learners extra time to master skills. Because the TARGET framework

4 provides guidance as to specific environmental structures that emphasize different achievement

5 goals, it has proved a useful model for researchers interested in manipulating the motivational

6 climate in the physical domain.

$7 \quad$ Motivational Climate Interventions

8 Reviews of motivational climate research in physical activity highlight the prevalence of 9 cross-sectional studies that seek to identify the correlates of perceived mastery and performance

10 climates (see Duda \& Whitehead, 1998; Harwood et al., 2008; Ntoumanis \& Biddle, 1999). This

11 comprehensive body of work provides support for the positive or adaptive correlates (e.g.,

12 confidence, enjoyment, task orientation) associated with mastery climate, whereas performance

13 climate is often not associated with such outcomes, instead being linked with negative or

14 maladaptive consequences (e.g., anxiety, boredom, ego orientation). Therefore, on the basis of

15 theory (Ames, 1992a, b; Epstein, 1989) and substantial correlational research in physical activity

16 settings, it has been proposed that interventions should seek to promote mastery climates in order

17 to enhance motivation (Duda, 1996; Harwood et al., 2008).

18 Ntoumanis and Biddle (1999), in their review of motivational climate, identified four

19 short-term and three long-term interventions that sought to manipulate the psychological

20 environment of participants engaged in a variety of physical activities. Only one study

21 (Theeboom, De Knop \& Weiss, 1995) adopted the TARGET framework and found support for

22 the hypothesized benefits of creating a mastery climate i.e., higher levels of enjoyment and

23 motor skills among the mastery group compared to the traditional group. Narrative reviews of

24 achievement goal research in physical activity reveal that, since 1999, correlational research has 
1 continued to flourish, and authors have called for stronger designs that facilitate the inference of

2 cause and effect (Duda, 2001; Duda \& Whitehead, 1998; Harwood et al., 2008; Roberts, 2001).

3 Although not as prevalent as cross-sectional investigations, a number of intervention studies

4 have been conducted into the effects of manipulating mastery climate on cognitive, affective and

5 behavioral outcomes. We argue that, over a decade later, there is a requirement to examine the

6 collective empirical yield. Thus, the purpose of the present paper was to examine effect sizes

7 across studies on different outcomes, to provide some indication of a summary effect for both

8 positive and negative outcomes, and to identify the influence of moderating variables. In

9 undertaking this research endeavor, we hoped to provide a critique of this area to assist

10 researchers in the planning, delivery and reporting of future interventions. Moreover, in

11 responding to the interests of practitioners working in sports and PE settings, we wanted to

12 address the question: 'Do interventions work and what determines their effectiveness?' We

13 expected that mastery climate interventions would result in significant positive effects on

14 adaptive affective, behavioral, and cognitive motivational outcomes and significant negative

15 effects on maladaptive outcomes. Where analyses revealed heterogeneity among effect sizes

16 (i.e., results across studies were inconsistent), we analysed the influence of a number of

17 moderators. However, we did not set, a priori, hypotheses in relation to potential moderating

18 influences. Instead, coding methods established by Brown, Upchurch, \& Acton (2003) were used

19 to extract descriptive information listing characteristics of interest. Based on the descriptive

20 information collected, three categories were established including methodological features,

21 participant features, and study features. Information regarding the specific features can be found

22 in the methods section.

\section{Methods}

\section{Literature Search \& Inclusion Criteria}


A literature search was conducted in three phases that included a) an electronic database

2 search, b) a search for review articles and c) a search of the reference sections in articles

3 determined to be relevant from the previous searches ( $\mathrm{a} \& \mathrm{~b}$ ). Electronic database searches were

4 performed in Academic Search Elite, ArticleFirst, ERIC, Medline, OmniFile, Physical Education

5 Index, Proquest Dissertations and Theses, PsychINFO, PsychARTICLES, and SportDiscus using

6 variations of the keywords intervention, achievement motivation, achievement goal theory,

7 motivational climate, mastery climate, performance climate, and TARGET. Articles retained for

8 the current meta-analysis met the following inclusion criteria: (a) Published and unpublished

9 literature in the English language from January 1, 1992 to August 1, 2010; (b) use of a

10 motivational climate intervention following the TARGET structure established by Ames (1992b)

11 and Epstein (1988, 1999); (c) interventions conduced in school-based physical education settings

12 and reporting measurements for student outcomes as a result of the intervention; (d) studies using

13 a control group or control measure, (e) articles reporting quantitative descriptive and/or

14 inferential statistics that would allow for calculation or estimation of an effect size, and (f)

15 studies reporting reliability (e.g., Cronbach Alpha's) and validity (e.g., confirmatory factor

16 analysis results [CFA] or the use of previously established measures that have used CFA)

17 coefficients of motivational climate instruments.

18 Search procedures generated 2190 potential studies for evaluation and initial decisions

19 regarding article retrieval were based on review of abstracts. After the abstract screening process,

20 a total of 57 studies were identified as potential sources for data collection and retrieved for

21 detailed analysis. The search process also produced dissertations and theses that were later

22 published in refereed journals, therefore, journal articles were used to extract data and prevent

23 redundancy. A total of 22 studies with 24 independent samples were included in the meta-

24 analysis. 
Data extraction forms following established meta-analytic procedures were then used to

2 code data relevant to the current study (Brown, Upchurch, \& Acton, 2003; Wilson \& Lipsey,

3 2001). Two coders reviewed and evaluated articles on 12 characteristics that were classified into

4 three sections (a) methodological features, (b) participant features, and (c) study features.

5 Methodological features provided details concerning methods used during the intervention and

6 included: 1) Training of teachers or instructors to deliver intervention (reported hours spent

7 training individuals to conduct intervention, Not Specific (NS)-indicated training but did not

8 specify time, Not Reported (NR)-did not report training procedures; 2) Duration in weeks

9 marked the overall intervention time period and in cases with year-long interventions time in

10 school was approximated at 40 weeks; 3) The use of a follow-up measure (yes or no) examining

11 outcomes after intervention; 4) The use of a manipulation check of motivational climate (yes or

12 no) prior to start of intervention; 5) TARGET intervention was conducted using all (full) or some

13 of the components (partial) of a mastery motivational climate; 6) Intervention intensity examined

14 how frequently students $(1=$ greater than or equal to 3 days of the week, $2=$ less than or equal to

152 days of the week, $3=$ biweekly, $4=$ monthly) were involved in the mastery climate intervention.

16 Participant features provided information concerning 7) Overall sample size; 8) Participant mean

17 age in years; 9) Participants grade level in school (E=Elementary ages 5 to 11.99 years,

$18 \mathrm{M}=$ Middle School ages 12 to 14.99 years, and $\mathrm{H}=$ High School ages 15 to 18 years) when the

19 intervention was conducted; and 10) Country represented geographical location of participants

20 involved in intervention. Study features included: 11) Publication status (published or

21 unpublished); 12) Outcome measures regarding data collection (self-report and/or teacher report,

22 objective measure, or combination); and 13) Overall study effect size.

\section{Effect Size Calculations}


Data were entered into Comprehensive Meta Analysis (CMA) version-2 software

2 (Borenstein, Hedges, Higgins, \& Rothstein, 2005) which was used to compute all effect sizes.

3 CMA provides many (more than 100) data entry options allowing flexibility during analysis to

4 overcome insufficient information not provided in the literature. Data entry formats used in this

5 study to calculate effect sizes included variations of both matched and unmatched designs across

6 posttest, pre-post contrasts, and gain scores. When descriptive data such as means and standard

7 deviations were not available, estimates of effect size calculations were based on $F, t, r$, or $p$ -

8 values (Rosenthal, 1994). Each study was the unit of analysis and contributed one independent

9 effect size to the meta- analysis. If a study contained more than one relevant effect size (multiple

10 outcomes per study) the standard procedure was to average those scores providing one overall

11 (combined) calculation (Borenstein et al., 2009; Cooper, 1998). Additionally, outcome analyses

12 were used to determine summary effects of a single outcome and the summary treatment effect

13 for that outcome was the mean calculation across studies measuring that outcome (Cooper,

14 1998). For example, several studies reported information on situational outcomes (mastery and

15 performance climate perceptions) and dispositional outcomes (ego and task orientation). The

16 overall treatment effect was an average of both dispositional and situational variables and the

17 outcome analyses provided a summary effect for each dispositional and situational outcome

18 variable. Hedges $g$ was selected as the measure of effect size to provide a conservative estimate

19 of effect due to small sample sizes $(k<20)$ (Hedges \& Olkin, 1985) and was calculated by CMA

20 with the following formula:

$$
g=d\left[1-\frac{3}{4\left(n_{1}+n_{2}\right)-9}\right]
$$

21 There are two primary models that can be employed to determine statistical assumptions of error

22 when conducting a meta-analysis (Hedges \& Vevea, 1998). A fixed effects model suggests that 
1 all studies in the meta-analysis share a common effect and differences are a result of within study

2 error (sampling error), whereas a random effects model makes the assumption that there are both

3 within study error and between study variance (Borenstein et al., 2009). A random effects model

4 (Hedges \& Olkin, 1985; Hedges \& Vevea, 1998; Field, 2003) was selected for the analysis due

5 to variation between intervention methods, potential sampling error, and the possibility of

6 random unexplained variance between studies. Standardized mean differences were adjusted by

7 the inverse weight of the variance to prevent sample size from inflating study weights and

8 allowing for a more accurate calculation of the overall effect size (Borenstein, Hedges, Higgins,

9 \& Rothstein, 2009; Hedges \& Olkin, 1985; Shaddish \& Haddock, 1994). An a priori power

10 analysis determined that there were sufficient studies in the meta-analysis to detect moderate to

11 large effects.

12 Heterogeneity of Variance

13 When using a random effects model there is an assumption that the true effect size will

14 vary between studies, therefore, several indicators were used to assess heterogeneity of variance.

15 The $Q$-test serves as a significance test and is based on critical values for a chi-square $\left(\chi^{2}\right)$

16 distribution. Significant $Q$-values indicate heterogeneity, or that variability across the effect sizes

17 is greater than what would have resulted from chance. Effect size distributions that are

18 heterogeneous indicate a large variability and allow for study of moderator variables to provide a

19 more accurate estimate of study dispersion. The computations produced from a moderator

20 analysis compartmentalize the total $Q_{T}$-value variance by calculating between $\left(Q_{B}\right)$ and within

$21\left(Q_{W}\right)$ values. Significant $Q_{B}$ values indicate moderator variance that can be attributed to

22 systematic between-study differences and require t-test or an analysis of variance technique

23 described by Hedges \& Olkin (1985) to identify between group differences. When interpreting

24 the $Q$-statistics $\left(Q_{\text {Total }}\right.$ and $\left.Q_{\text {Between }}\right)$ and corresponding $p$-values, all heterogeneity statistics $\left(\tau^{2}\right.$ 
1 and $I^{2}$, see next paragraph for descriptions) should be considered for interpretation, as significant

$2 p$-values only indicate that true effects vary between studies but do not provide information on

3 the magnitude of dispersion (Borestein et al., 2009). The final consideration was the influence of

4 a random effects model on moderating variables when model assumptions are violated as there is

5 a potential to overestimate error (Overton, 1998) when sample sizes are small (Field, 2001). To

6 prevent type I errors we set a conservative alpha level $(\alpha<.01)$ when interpreting significant

7 moderators.

$8 \quad$ CMA version-2 software provides four statistics $\left(Q, \tau^{2}, \tau\right.$, and $\left.I^{2}\right)$ to assess sub-group

9 differences. Besides the $Q_{T}$-value there were two additional statistics that were used to interpret

10 heterogeneity that included tau-squared $\left(\tau^{2}\right)$ and I-squared $\left(I^{2}\right)$. The $\tau^{2}$ statistic is used by CMA to

11 calculate weights and yields an estimate of total variance between studies in a random effects

12 model. Larger $\tau^{2}$ values reflect the proportion of variance that can be attributed to real

13 differences between studies. When the number of effect sizes in a sub-group was small $(k \leq 5)$

14 estimates of $\tau^{2}$ are likely to be imprecise and the standard procedure was to use a pooled estimate

15 of variance for all calculations of moderators (Borenstein et al., 2009). The $I^{2}$ statistic is the ratio

16 of excess dispersion to total dispersion and can be interpreted as the overlap of confidence

17 intervals explaining the total variance attributed to the covariates (Higgins, Thompson, Deeks, \&

18 Altman, 2003). Values closer to zero represent random error and values that move away from

19 zero provide an opportunity to analyse variance by covariates. Interpretation of the $I^{2}$ statistic

20 indicates low $(25 \%)$, moderate $(50 \%)$, and high $(75 \%)$ relative variance with higher values

21 requiring techniques (i.e., moderator analysis or meta-regression) to provide explanations

22 (Borenstein et al., 2009; Higgins et al., 2003).

\section{Outlier Analysis \& Publication Bias}


Outlier analysis was examined by interpretation of relative residuals and by a "one-study removed" procedure that is available in CMA. Any study that was identified as an outlier (a large residual value $\mathrm{z} \leq$ or $\geq 1.96$ ) was examined in a "one study removed" analysis, studies were not removed if they did not substantially impact the effect size $g$ and results were within or near the $95^{\text {th }}$ confidence interval. Publication bias was controlled for by visual inspection of a funnel plot, the Trim and Fill procedure (Duval \& Tweedie, 2000) and Fail Safe- $N$ calculation (Rosenthal, 1979). The funnel plot provided a visual representation of publication bias that was based on a symmetrical distribution of data points about the mean effect size. A funnel plot graphs studies

9 according to standard error (y-axis) and effect size (x-axis) with larger studies appearing toward

10 the top of the plot (less error) and smaller studies (more error) toward the bottom. Symmetrical

11 plots can be interpreted as a lack of publication bias, however, asymmetrical data are adjusted by

12 using Duval and Tweedie's (2000a) Trim and Fill procedure on a precision plot. The Trim and

13 Fill procedure is an iterative process that adjusts overall effect size by identifying the number of 14 missing studies (with negative effects) that would balance the plot to provide an unbiased 15 estimate of effect size (Duval \& Tweedie, 2000b). "Fail safe N" was used as an additional

16 precaution and determines the number of non-significant missing studies that would be needed to 17 nullify significant results (Rosenthal, 1979).

\section{Outcome Analyses}

Due to the large number of student outcome variables and relatively few studies for each

20 outcome, an approach resembling methods employed by Biddle, Wang, Kavussanu, \& Spray

21 (2003) and Ntoumanis \& Biddle (1999) were used to condense and summarize findings that

22 represented affective, behavioral, and/or cognitive outcomes. The process used to define and sort

23 outcome variables included gathering information on instruments used to collect data from

24 studies meeting inclusion criteria. Outcomes that were measured by an instrument, subscale, or a 
1 few items were then grouped according to the construct. For example, there were five separate

2 measures used to collect information on competence and confidence. These measures included

3 the Intrinsic Motivation Inventory (IMI; McAuley, Duncan, \& Tammen, 1989), Competitive

4 State Anxiety Inventory-2 (CSAI-2; Martens, Vealey, \& Burton, 1990), Physical Self-Perception

5 Profile (PSPP; Fox \& Corbin, 1989), Pictorial Scale of Perceived Competence and Social

6 Acceptance (PSPCSA; Harter, 1982), and the Physical Education Teachers' Emphasis on

7 Achievement Goals Questionnaire (PETEAGQ; Papaioannou, Milosis, Kosmidou, \& Tsigilis,

8 2007). Field's (2001, 2005) Monte Carlo simulations of meta-analytic approaches found that

9 using Hedges and Olkin's (1985) and Hedges and Vevea's (1998) random effects approach when

10 data were heterogeneous did not control for type I errors with fewer than 15 studies. Based on

11 Field's (2001, 2005) findings, in addition to Borenstein and colleagues' (2009) suggestions on

12 reporting standards, we have provided summary effects for each outcome where there were a

13 critical number (three or four studies) of studies measuring a specific outcome, along with a

14 conservative interpretation.

15 Affective outcomes measured included attitudes (Ajzen, 1988; Carlson, 1995;

16 Christodoulidis, Papaioannou, \& Digidelidis, 2001; Treasure, 1993, 1997), boredom (Duda \&

17 Nicholls, 1992; Treasure, 1997), commitment/ dedication (Cecchini, Gonzalez, Carmona,

18 Arruza, Escarti, \& Balague, 2001; Papaioannou \& Theodorakis, 1996; Theodorakis, 1994), and

19 enjoyment/satisfaction (Duda \& Nicholls, 1992; Duda, Fox, Biddle, \& Armstrong, 1992;

20 McAuley, Duncan, \& Tammen, 1989; Treasure, 1997). Behavioral outcomes measured were

21 health/fitness related variables (Bowler, 2009; Christodoulidis et al. 1992; Cramer, 2000;

22 Digelidis, 2003) and skills (Boone, 1995; Cramer, 2000; Martin, Hastie, \& Rudisell, 2009;

23 Solmon, 1996; Valentini \& Rudisell, 2004a, 2004b). Cognitive outcomes measured included

24 achievement goal (task/ego) orientations (Ballague \& Roberts, 1991; Duda \& Nicholls, 1992; 
1 Roberts, Treasure, \& Balague 1998; Walling \& Duda, 1995; Treasure \& Roberts, 1994), anxiety

2 (Barkoukis, 2004; Martens, Burton, Vealey, Smith, \& Bump, 1990; Papaioannou, 1994),

3 competence/confidence (Fox \& Corbin, 1989; Harter \& Pike, 1984; Martins et al., 1990;

4 McAuley, Duncan, \& Tammen, 1989; Morgan \& Kingston, 2008; Papaioannou, 1994, 2007;

5 Weigand \& Burton, 2002), competitive and learning strategies (Morgan \& Carpenter, 2002;

6 Papaioannou, 1994; Solmon \& Boone, 1993), motivational climate (mastery and performance)

7 perceptions (Papaioannou, 1994, 1998, 2007; Seifritz, Duda, \& Chi, 1992), perceptions of ability

8 (Duda \& Nicholls, 1992; McAuley, Duncan, \& Tammen, 1989), and perceptions of effort (Duda

9 \& Nicholls, 1992; McAuley, Duncan, \& Tammen, 1989).

Results

11 The primary purpose of the current study was to determine the overall effectiveness

12 across all outcomes of motivational climate interventions and the secondary purpose was to

13 determine the effect of motivational climate interventions (TARGET) on specific affective,

14 behavioral, and cognitive outcomes in school-based physical education. There were a total of 22

15 studies with 24 independent samples that included 4932 participants meeting inclusion criteria.

16 The overall inter-rater agreement between two coders was $92.3 \%$ and ranged from $75 \%$ to $100 \%$

17 across the 12 characteristics coded and extraction of descriptive and inferential statistics. There

18 were a total of 23 disagreements and of those disagreements seven were factual disagreements

19 that were corrected and 16 interpretation disagreements that were uncorrected. An objective third

20 coder evaluated each of the interpretations disagreements and the coding value or data extraction

21 value used was based on the simple majority (two coders). Figure 1 provides an overall

22 presentation of the search strategy and Table 1 displays the coded methodological, participant,

23 and study features as well as each study's overall treatment effect. When interpreting the

24 treatment effects Cohen's (1988) criteria were used for interpretation of standardized mean 
1 differences and summarized effect sizes as small ( $\leq .20)$, medium (.50), and large ( $\geq .80)$. Positive

2 effect sizes are interpreted as treatment groups (mastery motivational climate) having stronger

3 results than control groups or groups exposed to performance climate manipulations. Negative

4 treatment effects indicated that the control group or performance climate group produced larger

5 outcome results than the mastery climate group.

INSERT TABLE 1 AND FIGURE 1 ABOUT HERE

\section{$7 \quad$ Random Effects Model Results}

The average treatment effect for all TARGET intervention studies was small $(\mathrm{g}=0.103$;

$9 \mathrm{SE}=0.035 ; 95 \%$ C.I. $=0.034,0.171 ; \mathrm{p}=0.003)$ and represented about one tenth a standard

10 deviation advantage for treatment groups over control groups. Table 2 presents an overview of

11 the relevant statistics used when evaluating the overall effect. Review of the homogeneity

12 statistics revealed a significant heterogeneous distribution $\left(Q_{T}=38.59, p=0.022 ; I^{2}=40.40\right)$

13 making it necessary to explain between study variation though moderator analyses of

14 characteristics coded for studies. In addition, an outlier analysis was conducted through

15 evaluation of residual values and found one independent sample (Valentini \& Rudisell., 2004b)

16 to be an outlier $(\mathrm{z}=2.09)$, therefore, a "one study removed" procedure was performed. The

17 single effect size was retained in the analysis as results indicated a small change (-.006) in the

18 effect size $(\mathrm{g}=0.097)$ remaining within the $95 \%$ confidence interval. Publication bias was

19 deemed marginal as a result of a symmetrical funnel plot, no studies being added during the Trim

20 and Fill procedure, and a Fail Safe N value calculation of 98 studies that would be needed to 21 nullify a significant $\alpha$-level $(\mathrm{p}<.05)$.

\section{Outcome Analyses}


In summary, outcome analyses generated positive and negative effects ranging from a

2 low of -.274 to a high of 0.599 . The diversity of outcomes and limited number of studies meeting

3 inclusion criteria compelled the authors to employ procedures (see Biddle et al., 2003)

4 combining measures with similar constructs and having at least three effect sizes for each

5 outcome. Results were consistent with Achievement Goal Theory literature producing positive

6 findings for adaptive outcomes and negative results for maladaptive outcomes (Biddle et al.

7 2003; Hardwood et al., 2009). Maladaptive outcomes such as anxiety, boredom, competitive

8 strategies, ego orientation, and perceptions of a performance climate were largest for control

9 groups or groups exposed to performance climate conditions. Adaptive outcomes that were

10 positive for groups experiencing a mastery climate treatment included attitude, commitment,

11 enjoyment, competence/confidence, mastery climate perceptions, perceptions of effort, and task

12 orientation. The largest positive treatment effects were found for attitude $(N=1634, k=4, g=$

13 0.599), health/fitness $(N=1513, k=4, g=0.492)$, and skills $(N=705, k=7, g=0.395)$ with the

14 most negative effect sizes found for the outcomes boredom $(N=288, k=3, g=-0.274)$, anxiety

$15(N=728, k=3, g=-0.246)$, and perceptions of a performance climate $(N=3012, k=13, g=-$

16 0.239). Moderator analyses were needed for most outcome variables $\left(Q_{B} \leq .01\right)$, however, there

17 were insufficient data for some outcomes to perform moderator analyses that would generate a

18 precise estimate of the combined effect (Borenstein et al, 2009). Therefore, we chose only to

19 report the summary effect for each outcome and not to perform moderator analyses.

Affective outcomes. Mastery climate interventions produced small to moderate negative

21 and positive treatment effects for affective outcomes. Interpretation of these results suggest that

22 TARGET interventions produce between one seventh $(g=0.149)$ to greater than one half $(g=$

23 0.599) a standard deviations advantage on adaptive outcomes for groups exposed to mastery

24 climate conditions. Outlier analyses for all affective outcomes produced no large residual values, 
1 however, publication bias statistics (Fail-Safe $N$ ) indicated low tolerance for suggesting caution

2 when interpreting affective outcome results for boredom.

Behavioral outcomes. The largest overall outcome advantage for groups exposed to

4 mastery climate TARGET manipulations were found in behavioral outcomes. Health and fitness

5 outcomes (i.e., heart rate, cardiovascular fitness, exercise frequency, nutrition behaviors) as well

6 as skill-based outcomes (badminton, basketball, juggling, and practice conditions) produced

7 treatment effect sizes $(g=0.395$ and $g=0.492)$ that were small to moderate. Observation of

8 heterogeneity statistics revealed that distributions were homogeneous (non-significant $Q_{T}$-values,

$9 \mathrm{p}>.05)$ or that studies measuring health/fitness and skill outcomes produced similar findings and

10 no moderator analyses were needed to explain variance between studies. Publication bias was

11 unlikely as Fail Safe $N$ calculations for both health/fitness (52 studies) and skills (35 studies)

12 indicated several studies were needed to produce non-significant results.

13 Cognitive outcomes. Cognitive outcomes were most frequently measured in studies and

14 included treatment effects on student variables such as confidence/competence $(k=9)$, ego

15 orientation $(k=14)$, mastery climate perceptions $(k=13)$, performance climate perceptions $(k=12)$,

16 and task orientation $(k=14)$. Desired treatment effects were positive small gains in mastery

17 climate groups for the adaptive outcomes commitment $(g=.183)$, confidence/ competence

$18(g=.118)$, learning strategies $(g=.285)$, perceptions of a mastery climate $(g=.315)$, and task

19 orientation $(g=.181)$. In summary, the maladaptive cognitive outcomes anxiety, competitive

20 strategies, ego orientation, and perceptions of a performance climate produced small negative

21 effects ranging from -0.065 to -0.246 with homogeneity statistics indicating heterogeneous $\left(Q_{T}<\right.$.

$2205)$ distributions and large portions of variance $\left(I^{2}>70\right)$ that could be explained by moderator

23 analyses. The only cognitive outcomes that could be interpreted with confidence that publication

24 bias was not present were task-orientation and perceptions of a mastery and performance 
1 climates. These results indicated that overall summary effects for maladaptive outcomes were

2 not robust and further study is needed to provide an accurate estimate of effect size for most 3 cognitive outcomes.

4 Moderator Analyses

Heterogeneity statistics for the random effects model confirmed that there was a

6 heterogeneous $\left(Q_{T}=38.59, p<.05\right)$ distribution and that a moderate level $\left(I^{2}=40.40\right)$ of between

$7 \quad$ study variation existed to justify conducting subgroup analyses for coding characteristics. Tables

82 and 3 present the results from moderator analyses on intervention characteristics (Table 2),

9 participant characteristics (Table 3), and study characteristics (Table 3). While all analyses

10 produced overall trends (treatment groups > control groups, $\mathrm{p}<.05$ ) for specific moderators,

11 there were no statistically significant differences $(p<.01)$ between moderators.

12 Methodological features. While no significant differences within methodological

13 moderators were present, there were several methodological trends including reported training

14 time $(g=.112, Z=2.639, p<.05)$ for individuals (teacher/researchers) delivering TARGET

15 interventions, motivational climate interventions longer than eight weeks $(g=.178, Z=2.434, p<$

$16.05)$, and TARGET interventions employing all the characteristics $(g=.150, Z=3.500, p<.05)$ of

17 a mastery motivational climate intervention. Studies conducting follow-up intervention measures

$18(g=.231, Z=2.838, p<.05)$ and employing a manipulation check $(g=.165, Z=2.462, p<.05)$

19 produced larger treatment effects than interventions not conducting follow-up measures $(g=$ $20.072, Z=2.028, p<.05)$ or using manipulation checks. $(g=.095, Z=1.664, p<.05)$. Overall, 21 there were small positive treatment effects.

\section{INSERT TABLE 3 ABOUT HERE}

Participant features. Level in school (Elementary School, Middle School, or High

24 School) and country (Brazil, Finland, Greece, Spain, UK, or US) were the primary categories for 
1 participant analysis There was a significant treatment effect $(Z \leq .05)$ for students at the

2 Elementary School level $(g=0.407, Z=3.710, p<.05)$, however, there were no moderator

3 differences $\left(Q_{B}=8.840, p>.01\right)$ when compared to Middle School $(g=0.068, Z=0.940, p>.05)$

4 or High School students $(g=0.066, Z=1.896, p>.05)$. The moderator trends for country had

5 the largest treatment effects for participants in Brazil $(g=0.563, Z=2.610, p<.05)$ and the US

$6(g=0.239, Z=2.962, p<.05)$ than for participants in Finland $(g=-0.005, Z=-0.039, p>.05)$,

7 Greece $(g=0.058, Z=1.238, p>.05)$, Spain $(g=-0.084, Z=-0.480, p>.05)$, or the UK $(g=$

$80.089, Z=1.378, p>.05)$. Results from both participant and study characteristics can be found in

$9 \quad$ Table 3 and Table 4.

\section{INSERT TABLE 4 ABOUT HERE}

Study features. The moderator analysis for type of study found that unpublished $(g=$

$120.251, Z=2.145, p<.05)$ reports had larger treatment effects than unpublished $(g=0.087, Z=$

$132.423, p<.05)$, however, no significant differences were present $\left(Q_{B}=1.794, p>.01\right)$. Results

14 from the outcome measures analysis determined studies using both (combination) self-report and

15 objective methods in data collection had larger treatment effects $(Z=3.169, p<.05)$ than studies

16 only using self-report measures with no significant differences between either moderator

$17\left(Q_{B}=3.242, p>.01\right)$. Overall results from study feature moderators found small to marginal

18 treatment effects

\section{Discussion}

The purpose of our literature synthesis was twofold and focused on the effectiveness of

21 motivational climate interventions and moderating factors that contributed to positive or negative

22 results in physical education contexts. Our results found an overall positive treatment effect for

23 groups and participants exposed to a mastery motivational climate and negative effects for

24 untreated control groups or performance climate conditions. More specifically, TARGET 
1 strategies used to manipulate an environment to favor mastery conditions have small to moderate

2 treatment effects for affective, behavioral, and cognitive outcomes. These findings support our

3 hypotheses and are consistent with motivational climate literature that shows positive effects for

4 adaptive outcomes and negative effects for maladaptive outcomes across affective, behavioral,

5 and cognitive variables. Consequently, there are several factors that should be considered when

6 designing and implementing future motivational climate interventions. If motivational processes

7 underpin student participation in activity and learning, future interventions should provide more

8 empirical evidence to support instructional strategies that facilitate adaptive motivational

9 processes.

10 Outcome measures provided information concerning how data were collected from the

11 participants. Nine studies selected to use self-report measures while the other 15 studies used a

12 combination of self-report and objective measures. The difference in overall effectiveness across

13 all outcomes between the two methods used to collect data from students was non-significant (p

$14>.01)$, favoring a combination $(g=.189)$ over self-report $(g=.057)$ methods. Analysis of the types

15 of outcome variables that were intended for measurement were insightful concerning the

16 outcome measure and outcome focus for future research. In the current study, all interventions

17 measured some type of cognitive outcome, nine studies investigated behavioral outcomes, and 13

18 studies collected data on affective variables. Research on AGT connects situational processes to

19 several affective, behavioral, and cognitive outcomes but to date there is a shortage of data

20 concerning the influence of motivational climate interventions on affective and behavioral

21 variables. Equally important is the effect of situational achievement goals on learning, as most

22 educational research on competence-based goals has expectations attached to student

23 achievement in learning contexts (Chen \& Ennis, 2004). Student learning can be measured in

24 affective, cognitive, and psychomotor domains but in the current review there were only five 
1 studies (Cramer, 2000; Solmon 1996; Valentini \& Rudisell, 2004a, b) that directly measured

2 psychomotor learning as a result of employing a mastery climate intervention. Physical

3 education promotes lifetime involvement in physical activity and AGT research has enhanced

4 our understanding of student perceptions that are attached to specific situational influences that

5 engage students in a learning context. However, what remains unclear is how students use

6 competence based information received from their motivational climate perceptions in physical

7 education to influence participation in lifetime physical activity.

8 Recommendations for Future Intervention Research

9 Methodological features. Several substantive features were explored in an attempt to 10 explain the current findings and provide suggestions for future motivational climate

11 interventions. With regard to the methodological features, an important factor that underpins 12 successful manipulation of motivational climate is the training of teachers or those providing 13 instruction to students in physical education. All studies provided some detail concerning 14 TARGET framework training, however, only five of the 24 studies provided detailed information

15 on time spent and specific methods in preparing teachers to deliver the TARGET framework.

16 These methods included training seminars, pre-designed units or lessons, video analysis or

17 systematic coding, or combinations of the various strategies. Nevertheless, absent from most of

18 the studies are descriptions concerning teacher attitudes, beliefs, and teaching practice before and

19 after interventions as these teacher variables directly influence student outcomes (Biddle, 2001;

20 Ennis, 2003). More information is needed regarding the amount of time involved in training as

21 well as the specific strategies that reinforce the delivery of a TARGET framework in future

22 research to fully assess the effect of mastery climate interventions on student motivation.

23 The link between training and the intervention delivery process (intervention duration

24 and intervention intensity) is critical to maximize both teacher and student outcomes. Analysis of 
1 these intervention characteristics found four studies that conducted lengthy interventions

2 (majority of the school year) and nine studies utilized interventions that covered a unit of work

3 (learning) in physical education settings. Also apparent was the diverse nature in intensity of

4 delivery, as studies conducted for shorter periods of time (more mastery sessions per week) were

5 more frequent than longer TARGET interventions (fewer mastery sessions per week). Another

6 important consideration for future TARGET interventions is to balance quality (intervention

7 intensity or frequency of sessions and personnel training) as well as quantity (intervention

8 duration). Educational settings such as physical education are interested in the long term effects

9 and by identifying the quantity and quality of specific training strategies and the amount of time

10 (longitudinal studies) invested in preparing teachers, research could start to isolate and enhance

11 strategies that better facilitate the influence of TARGET structures.

12 Taking baseline measurements during an experiment constitutes an important

13 methodological feature and motivational climate manipulation checks provide information on

14 student perceptions prior to an intervention being conducted. Without a climate manipulation

15 check, student outcomes cannot be directly attributed to the treatment being applied. Our review

16 found five studies that did not report a climate manipulation check, therefore, results concerning

17 student outcomes may or may not be attributed to exposure (or lack thereof) to a mastery

18 motivational climate. Equally important to research on motivation climate are the long term

19 effects on student motivation as a result of being exposed to a TARGET intervention. To date,

20 only three studies (four independent samples) used follow-up measures to determine treatment

21 effectiveness. Results were mixed with two studies (Christoloudis et al., 2001; Digidelidis et al.,

22 2003) finding no long term effects and one study (Valentini \& Rudisell, 2004) producing

23 significant treatment effects. The authors encourage future intervention studies to collect these 
1 pre-test, post-test, and follow-up measures to further our understanding of TARGET

2 interventions.

3 When analyzing the use of the TARGET structure to conduct interventions, 17 of the

4 studies meeting inclusion criteria employed a full (all components) TARGET module when

5 implementing mastery climate interventions as compared to seven studies using a partial (some

6 of the components) module during mastery climate interventions. Ames (1992a, b) and Epstein

7 (1988, 1989) provide specific strategies which can be used when employing the TARGET

8 framework to improve the motivational climate and these strategies appear to be connected to the

9 literature on the effective teaching principles in physical education (Rink, 2003). Both full and

10 partial interventions produced positive outcomes for mastery climates with full TARGET models

11 producing the strongest results in treatment groups. Additional studies using interventions to

12 promote mastery motivational climates would benefit by connecting process and product

13 research to specific pedagogical principles of effective teaching (process) to adaptive outcomes

14 (products).

15 Participant features. Analyses of the participant features produced the largest effect

16 sizes within the current investigation. The moderator analyses of grade in school (level)

17 produced significant results for elementary students (ages 5 to 11) and marginal treatment effects

18 for middle school (ages 12 to14), and high school (ages 15 to18) students. Elementary and high

19 school students were the least studied subgroups $(k=6)$ as compared to middle school $(k=12)$.

20 When analyzing the motives behind youth's declining interest in physical education, and in

21 general physical activity participation, understanding the spectrum of changes that occur during

22 each transitional time period from youth to adolescence is an important consideration. Additional

23 information is also needed concerning the gender and cultural contexts for physical education to

24 explore variance in outcome variables related to motivational climate. Given that our analysis 
1 found trends in country as a moderator of climate perceptions, we would suggest future studies

2 attempt to explore cultural, gender, and contextual factors of physical education. Results from

3 our study suggest that Brazil and the US produced strong treatment effects when compared to

4 other countries in which TARGET interventions were conducted. Information on contextual

5 factors such as curriculum and instructional delivery might provide an additional perspective on

6 participants concerning motivational climate perceptions in physical education. What is also

7 beginning to emerge from the literature is that, not only are teachers considered to be a pivotal

8 figure in determining motivational climate in physical education, but peers' influence can impact

9 climate perceptions especially during adolescence (Harwood \& Swain, 2001; Vazou, Ntoumanis

10 \& Duda, 2006). The developmental aspects related to motivational climate provide a compelling

11 argument on how students begin to conceptualize success (Nicholls, 1989) in physical education,

12 but equally important are changes related to health-related outcomes (i.e., decline in physical

13 activity and increase in sedentary behaviors) that occur during middle school years and beyond

14 (United States Department of Health and Human Services, 2008, 2010; United Kingdom

15 Department of Health, 2004). Future research might direct the focus on transitional periods, both

16 before and after, on a variety of affective, behavioral, and cognitive outcomes that the literature

17 has established as relevant.

18 Study features. Study characteristics that were analyzed as a part of the moderator

19 analyses included publication type (published or unpublished) and type of outcome measure (self

20 report and/or objective) that were used to collect information from the students. There were

21 seven studies (one conference presentation and six dissertations) identified in literature searches

22 meeting inclusion criteria, and of those studies, four were later published in peer reviewed

23 journals. Analysis of this moderator produced larger effects for unpublished ( $g=.246)$ than

24 published $(g=.089)$. The authors are unsure of the rationale concerning the decision not to 
1 publish, however, these studies did produce small to moderate positive treatment effects. The

2 outcome measure moderator for study features produced a noticeable difference between

3 TARGET interventions that used a combination approach (self-report and objective measures)

4 when compared to self-report approaches in data collection. Additionally, there has been a

5 precedent set that research conducted on motivational climate use interventions to provide

6 information that advances our knowledge and understanding on the influence of motivational

7 climate on outcome variables (Duda, 1993; Harwood et al. 2009). We would echo those

8 suggestions and in addition advocate for future studies to used combinations of measures to

9 collect data from participants being exposed to motivational climate manipulations.

\section{$10 \quad$ Conclusions}

11 When analyzing the motivational climate literature, more data are needed from teachers

12 and students to provide an overall perspective on what is happening within physical education

13 settings that preempts motivational processes. The authors understand that there are several

14 factors to consider when collecting data from students in schools, however, we would advocate

15 that future quantitative interventions provide information on all outcomes regardless of the

16 influence on publication merit. The most important consideration for the construct of motivation

17 and the situational influences that exist in physical education is that more information concerning

18 affective, behavioral, and cognitive learning outcomes is needed to provide a holistic perspective

19 to help teachers implement methods that will enhance student participation in lifetime physical 20 activity.

21 The overall summary of meta-analytic findings indicated that factors such as the lack of a

22 validated and reliable measurement tool for each component of TARGET, different measurement

23 tools for perceptions of climate, lack of standardized training policies and procedures for those 24 administering interventions, and inequity and inconsistent evidence for many affective, 
1 behavioral, and cognitive outcomes limit drawing firm conclusions on the positive effects of

2 motivational climate interventions. Additional methodological factors such as the unit of analysis

3 (class or individual) debate, conducting a priori power calculations, and employing balanced

4 group designs and (to the extent possible) randomized controlled trials could all improve the

5 effectiveness of motivational climate interventions. Clearly, more TARGET intervention studies

6 are requisite in physical education contexts. Interventions should be conducted with different

7 populations using specific strategies that address the unique demands of different environments

8 to provide a substantive review of the effectiveness of TARGET structures on student cognitions,

9 affect and behavior in physical education. 


\section{References}

2 References marked with an asterisk (*) indicate studies included in the meta-analysis.

3 Ajzen, I. (1988). Attitudes, personality, and behavior. Chicago, IL: Dorsey Press.

4 Ames, C., \& Ames, R. (1984). Goal structures and motivation. The Elementary School Journal, 85, 39-52.

6 Ames, C. (1992a). Classrooms: Goals, structures, and motivation. Journal of Educational $7 \quad$ Psychology, 84, 261-271.

Ames, C. (1992b). Achievement goals and the classroom motivational climate. In D. Schunk \& J. Meece (Eds.), Student perceptions in the classroom (pp. 327-348). Hillsdale, NJ, England: Lawrence Erlbaum Associates.

11 Ames, C. (1992c). Achievement goals, motivational climate, and motivational processes. In G. Roberts (Ed.), Motivation in sport and exercise (pp. 161-176). Champaign, IL: Human Kinetics.

14 *Barkoukis, V., Tsorbatzoudis, H., \& Grouis, G. (2008). Manipulation of motivational climate in physical education: Effects of a seven-month intervention. European Physical Education Review, 4, 367-387.

Biddle, S., Wang, J., Kavussanu, M., \& Spray, C. (2003). Correlates of achievement goal orientations in physical activity: A systematic review of research. European Journal of Sport Science, 3, 1-20.

*Boone, J.W. (1995). Achievement goals and motivational climates for physical education. 
1 Borenstein, M., Hedges, L., Higgins, J., \& Rothstein, H. (2005). Comprehensive meta-analysis:

A computer program for research synthesis (Version 2.0) [Computer software]. Englewood, NJ: Biostat.

Borenstein, M., Hedges, L., Higgins, J., \& Rothstein, H. (2009). Introduction to meta-analysis. Hoboken, NJ: Jon Wiley Publications.

Brown, S. A., Upchurch, S.L., \& Acton, G.J. (2003). A framework for developing a coding scheme for meta-analysis. Western Journal of Nursing Research, 25(2), 205-222.

Carpenter, P. J. \& Morgan, K. (1999) Motivational climate, personal goal perspectives, and cognitive and affective responses in physical education classes, European Journal of Physical Education, 4, 31-41.

*Cecchini, J., Gonzalez, C., Carmona, A., Arruza, J., Escarti, A., \& Balague, G. (2001). The influence of the physical education teacher on intrinsic motivation, self-confidence, anxiety, and pre- and post-competition mood states. European Journal of Sport Science, $1,1-11$.

Chen, A., \& Ennis, C.D. (2004). Goals, interests, and learning in physical education. Journal of Educational Research, 97, 329-338.

*Christodoulidis, T., Papaioannou, A., \& Digelidis, N. (2001). Motivational climate and attitudes towards exercise in Greek senior high school: A year-long intervention. European Journal of Sport Science, 1(4), 1-12.

Cohen, J. (1988). Statistical power analysis for the behavioral sciences (2nd ed.). Hillsdale, NJ: Erlbaum.

Cohen, J. (1992). A power primer. Psychological Bulletin, 112, 155-159.

Cooper, H. Synthesizing research: A guide for literature reviews $\left(3^{\text {rd }}\right.$ ed.). Thousand Oaks, CA: Sage 
1 Cooper, H., Hedges, L. V., \& Valentine, J. C. (2009). The handbook of research synthesis and 2 meta-analysis. ( $2^{\text {nd }}$ ed.). New York: Russell Sage Foundation.

$3{ }^{*}$ Cramer, S. (2000). Effects of motivational classroom climate on student goal orientation,

4 attitude toward physical education, cardiovascular fitness, and basketball shooting skill. $5 \quad$ Unpublished manuscript, Temple University.

6 Cury, F., Biddle, S. J., Famose, J. P., Goudas, M., Sarrazin, P., \& Durand, M. (1996). Personal 7 and situational factors influencing intrinsic interest of adolescent girls in physical education: A structural equation modeling analysis. Educational Psychology, 67, 293-309.

*Digedlidis, N., Papaioannou, A., Laparidis, K., \& Christodoulidis, T. (2003). A one-year intervention in 7 th grade physical education classes aiming to change motivational climate and attitudes towards exercise. Psychology of Sport and Exercise, 4, 195-210.

13 Dorobantu, M., \& Biddle, S. (1997) The influence of situational and individual goals on intrinsic motivation of Romanian adolescents towards physical education. European Yearbook of Sport Psychology, 1, 148-165.

Duda J., \& Nicholls, J. G (1992a) Sport and exercise motivation: A goal perspectives analysis.

19 Duda, J., \& Nicholls, J.G.(1992b). Dimensions of achievement in schoolwork and sport. Journal of Educational Psychology, 84, 290-299.

Duda, J.L., Fox, K.R., Biddle, S.B.J., \& Armstrong, N. (1992). Childrens achievement goals and beliefs about success in sport. British Journal of Educational Psychology, 62, 313323.

24 Duval, S., \& Tweedie, R. (2000a). A nonparametric "trim and fill" method accounting for 

publication bias in meta-analysis. Journal of American Statistical Association, 95, 89-98.

Duval, S., \& Tweedie, R. (2000b). Trim and fill: A simple funnel-plot-based method of testing for publication bias in meta-analysis. Biometrics, 56, 455-463.

Dweck, C. (1986). Motivational processes affecting learning. American Psychologist. Special Issue: Psychological science and education, 41, 1040-1048.

Epstein, J. (1989) Family structures and student motivation: A developmental perspective. In Epstein, J. (1988) Effective schools or effective students? Dealing with diversity. In R. Haskins Elliot, A., \& Dweck. C. (2005). Handbook of competence and motivation. New York: Guilford Press.

Dweck, C. (1999). Self-theories: Their role in motivation, personality, and development. Philadelpha: Psychology Press.

(1)

\& B. MacRae (Eds.), Policies for America's public schools Norwood (pp. 89-126). NJ: Ablex.

C. Ames \& R. Ames (Eds.), Research on motivation in education: Vol. 3 (pp. 259-295).

New York: AcademicPress.

Field, A. (2001). Meta-analysis of correlation coefficients: A Monte Carlo comparison of fixedand random- effects methods. Psychological Methods, 6, 161-180.

Field, A. (2003). The problems in using fixed effects models of meta-analysis on real world data. Understanding Statistics, 2, 105-124.

Field, A. (2005). Is the meta-analysis of correlation coefficients accurate when population correlationsvary. Psychological Bulletin, 10, 444-467

Fox, K., \& Corbin, C. (1989). The physical self-perception profile: Development and preliminary validation. Journal of Sport \& Exercise Psychology, 11, 408-430. 
1 Harter, S., \& Pike, R. (1984). The pictorial scale of perceived competence and social acceptance for young children. Child Development, 55, 1969-1982.

Harwood, C., Spray, C. M., \& Keegan, R. (2008). Achievement goal theories in sport. In T. Horn (Ed.), Advances in sport psychology (pp. 157-186). Champaign, IL: Human Kinetics.

Harwood, C., \& Swain, A.B.J. (2001). The development and activation of achievement goals in tennis: I. Understanding the underlying factors. The Sport Psychologist, 15, 319-341.

Hedges, L. V., \& Olkin, I. (1985). Statistical methods for meta-analysis. New York: Academic Press.

Hedegs, L.V., \& Vevea, J.L. (1998). Fixed and random effects models in meta-analysis. New York: Russell Sage Foundation.

Higgins, J. P. T., Thompson, S. G., Deeks, J. J., \& Altman, D. G. (2003). Measuring inconsistency in meta-analysis. British Medical Journal, 327, 557-560.

*Jaakkola, T., \& Liukkonen, J. (2006). Changes in students' self-determined motivation and goal orientation as a result of motivational climate intervention within high school physical education classes. International Journal of Sport and Exercise Psychology. Special Issue: Sport psychology in the school environment: An international perspective, 4, 302-324.

Lipsey, M., \& Wilson, D. (2001). Practical meta analysis. Thousand Oaks, CA: Sage Publications.

Martens, R., Vealey, R., \& Burton, D. (1990). Competitive anxiety in sport. Champaign, IL: Human Kinetics.

*Martin, E., Rudisill, M.E., \& Hastie, P. A. (2009). Motivational climate and fundamental motor skill performance in a naturalistic physical education setting. Physical Education 
and Sport Pedagogy, 14, 227-240.

2 McAuley, E., Duncan, T., \& Tammen, V. (1989). Psychometric properties of the intrinsic motivation inventory in a competitive sport setting: A confirmatory factor analysis. Research Quarterly for Exercise and Sport, 60, 48-58.

*Morgan, K., \& Carpenter, P. (2002). Effects of manipulating the motivational climate in physical education lessons. European Physical Education Review, 8, 207-229.

*Morgan, K., Kingston, K., \& Sproule, J. (2005). Effects of different teaching styles on the teacher behaviours that influence motivational climate and pupils' motivation in physical education. European Physical Education Review, 11, 257-285.

*Morgan, K., \& Kingston, K. (2008). Development of a self-observation mastery intervention programme for teacher education. Physical Education \& Sport Pedagogy, 13, 109-129.

Nicholls, J. G. (1984). Achievement motivation: Conceptions of ability, subjective experience, task choice, and performance, Psychological Review, 91, 328-346.

Nicholls, J. G. (1989). The competitive ethos and democratic education. Cambridge, MA: Harvard University Press.

Ntoumanis, N. \& Biddle, S. J. (1999). A review of motivational climate in physical activity, Journal of Sport Sciences, 17, 643-665.

Overton, R.C. (1998). A comparison of fixed-effects and mixed (random-effects) models for meta-analysis tests of moderator variable effects. Psychological Methods, 3, 354-379.

Papaioannou, A. (1994) 'Development of a Questionnaire to Measure Achievement Orientations in Physical Education', Research Quarterly for Exercise and Sport 65: 1120.

Papaioannou, A., \& Theodorakis, Y. (1996). A test of three models for the prediction of intention for participation in physical education lessons. International Journal of Sport 
Psychology, 27, 383-399.

*Papaioannou, A., \& Kouli, O. (1999). The effect of task structure, perceived motivational climate and goal orientations on students' task involvement and anxiety. Journal of Applied Sport Psychology, 1, 51-71.

*Papaioannou, A. G., Milosis, D., Kosmidou, E., \& Tsigilis, N. (2007). Motivational climate and

*Parish, L. E., Rudisill, M. E., \& Onge, P. M. S. (2007). Mastery motivational climate: Influence on physical play and heart rate in African American toddlers. Research Quarterly for

11 Roberts, G. C., \& Ommundsen, Y. (1996). Effects of goal orientations on achievement beliefs, achievement goals at the situational level of generality. Journal of Applied Sport Psychology, 19, 38-66. Exercise and Sport, 78, 171-178. cognitions, and strategies in team sport. Scandinavian Journal of Medicine and Science in Sport, 6, 46-56.

Roberts, G. C., Treasure, D. C., \& Kavussanu, M. (1996). Orthogonality of achievement goals and its relationships to beliefs about success and satisfaction in sport. The Sport Psychologist, 10, 398-408.

Roberts G. C., Treasure, D. C., \& Balague, G. (1998). Achievement goals in sport: The development and validation of the Perception of Success Questionnaire. Journal of Sports Sciences, 16, 337-347.

Roberts, G. C. (2001). Advances in motivation in sport and exercise. Champaign, IL: Human Kinetics.

Rosenthal, R. (1979). The file drawer problem and tolerance for null results. Psychological Bulletin, 86, 638-641. 
1 Rosenthal, R. (1994). Statistically describing and combining studies. In H. Cooper \& L. Hedeges (Eds.), The handbook of research synthesis (pp. 231-244). New York: Russell Sage Foundation.

Seifritz, J. J., Duda, J.L., \& Chi, L. (1992). The relationship between perceived motivational climate to intrinsic beliefs of success about basketball. Journal of Sport and Exercise Psychology, 17, 294-311.

Shadish, W. R., \& Haddock, C. K. (1994). Combining estimates of effect size. In H. Cooper \& L.Hedeges (Eds.) The handbook of research synthesis (pp. 261-281). New York: Russell Sage Foundation.

Solmon, M., \& Boone, J. (1993). The impact of student goal-orientation in physical education classes. Research Quarterly for Exercise and Sport, 64, 418-424.

*Solmon, M.A. (1996). Impact of motivational climate on students' behaviors and perceptions in a physical education setting. Journal of Educational Psychology, 88: 731-38.

Spray, C. M. (2000) Predicting participation in non compulsory physical education: do goal perspectives matter? Perceptual and Motor Skills, 90, 1207-1215.

Theodorakis, Y. (1994). Planned behavior, attitude strength, role identity, and the prediction of exercise behavior. The Sport Psychologist, 8, 149-165.

*Todorovich, J.R., \& Curtner-Smith, M.D. (2002). Influence of the motivational climate in physical education on sixth grade pupils' goal orientations. European Physical Education Review, 8, 119-138.

*Todorovich, J.R., \& Curtner-Smith, M.D. (2003). Influence of the motivational climate in physical education on third grade students task and ego orientations. Journal of Classroom Interaction, 38, 36-46. 
1 Treasure, D. (1993). A social-cognitive approach to understanding childrens achievement behavior, cognitions, and affect in competitive sport. Masters Thesis, University of Illinois-Urbana Champaign.

Treasure, D. C., \& Roberts, G. C. (1994). Cognitive and affective concomitants of task and ego goal orientations during the middle school years. Journal of Sport \& Exercise Psychology, 16, 15-28.

Treasure, D. C. (1997). Perceptions of the motivational climate and elementary school children's cognitive and affective response. Journal of Sport \& Exercise Psychology, $19,278-290$.

Vazou, S., Ntoumanis, N., \& Duda, J.L. (2006). Predicting young athletes motivational indices as a function of their perceptions of the coach- and peer-created climate. Psychology of Sport \& Exercise, 7, 215-233.

U.K. Department of Health (UKDOH). (2004). At least five a week: Evidence on the impact of physical activity and its relationship to health. London: U.K. Government.

U.S. Department of Health and Human Services (USDHHS). (2008). Physical activity guidelines for Americans. Washington, DC: U.S. Government.

U.S. Department of Health and Human Services (USDHHS). (2010). State indicator report on physical activity: National action guide. Atlanta: Centers for Disease Control.

*Valentini, N., \& Rudisill, M. E. (2004a). An inclusive mastery climate intervention and the motor skill development of children with and without disabilities. Adapted Physical Activity Quarterly, 21, 330-347.

*Valentini, N., \& Rudisill, M. E. (2004b). Motivational climate, motor-skill development, and perceived competence: Two studies of developmentally delayed kindergarten children. Journal of Teaching in Physical Education, 23, 216-234. 
1 *Viciana, J., Cervelló, E. M., \& Ramírez-Lechuga, J. (2007). Effect of manipulating positive and negative feedback on goal orientations, perceived motivational climate, satisfaction, task choice, perception of ability, and attitude toward physical education lessons. Perceptual and Motor Skills, 105, 67-82.

*Wallhead, T. L., \& Ntoumanis, N. (2004). Effects of a sport education intervention on Education, 23, 4-18.

Walling, M.D., \& Duda, J.L. (1995). Goals and their associations with beliefs about success by manipulating the motivational climate. European Journal of Sport Science, 2, 1-14. 


\section{Appendix A}

Meta Analysis Reporting Standards

\begin{tabular}{|c|c|c|}
\hline Paper Section/Topic & Description & Completed \\
\hline \multicolumn{3}{|l|}{ Title } \\
\hline & $\begin{array}{l}\text { 1. Make it clear that the report describes a research synthesis ad include } \\
\text { "meta-analysis", if applicable }\end{array}$ & Page 1,2 \\
\hline & 2. Footnote funding sources & N/A \\
\hline \multicolumn{3}{|l|}{ Abstract } \\
\hline & 1. The problem or relation(s) under investigation & Page 2 \\
\hline & 2. $\quad$ Study eligibility criteria & Page 2 \\
\hline & 3. Type(s) participants included in primary analysis & Page 2 \\
\hline & 4. $\quad$ Meta-analysis methods (fixed or random effects model) & Page 2 \\
\hline & $\begin{array}{l}\text { 5. Main results (including important effect sizes and any important moderators } \\
\text { of these effect sizes). }\end{array}$ & Page 2 \\
\hline & 6. Conclusions (including limitations) & Page 2,3 \\
\hline & 7. Implications for theory, policy, and/or practice & Page 2,3 \\
\hline \multicolumn{3}{|c|}{ 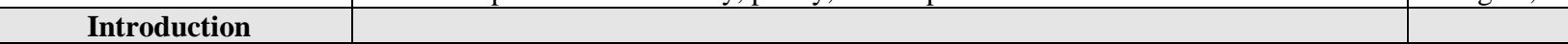 } \\
\hline & 1. Clear statement of the question or relation(s) under investigation & Page 7 \\
\hline & 2. $\quad$ Historical background & Pages 4-7 \\
\hline & $\begin{array}{l}\text { 3. Theoretical, policy, and/or practical issues related to the question or } \\
\text { relation(s) of interest }\end{array}$ & Pages 4-7 \\
\hline & $\begin{array}{l}\text { 4. Rationale for the selection and coding of potential moderators and mediators } \\
\text { of results }\end{array}$ & $\begin{array}{l}\text { Page } 9,13- \\
15\end{array}$ \\
\hline & $\begin{array}{l}\text { 5. Types of study designs used in the primary research, their strengths and } \\
\text { weaknesses }\end{array}$ & Pages 8-9 \\
\hline & $\begin{array}{l}\text { 6. Types of predictor and outcome measures used, their psychometric } \\
\text { characteristics }\end{array}$ & $\begin{array}{c}\text { Pages 8-9, } \\
13-15\end{array}$ \\
\hline & 7. Populations to which the question or relation is relevant & Page 8-9 \\
\hline & 8. Hypotheses, if any & Page 7 \\
\hline \multicolumn{3}{|l|}{ Method } \\
\hline \multirow[t]{5}{*}{$\begin{array}{c}\text { Inclusion/Exclusion } \\
\text { Criteria }\end{array}$} & $\begin{array}{l}\text { 1. Operational characteristics of independent (predictor) and dependent } \\
\text { (outcome) variable(s) }\end{array}$ & $\begin{array}{l}\text { Page 9, 13- } \\
\quad 15\end{array}$ \\
\hline & 2. $\quad$ Eligible participant populations & Page 8-9 \\
\hline & $\begin{array}{l}\text { 3. Eligible research design features (e.g., random assignment, minimal sample } \\
\text { size) }\end{array}$ & Page 8 \\
\hline & 4. $\quad$ Time period in which studies needed to be conducted & Page 8 \\
\hline & 5. Geographical and/or cultural restrictions & Page 8 \\
\hline $\begin{array}{c}\text { Moderator/Mediator } \\
\text { Analyses }\end{array}$ & $\begin{array}{l}\text { 1. Definition of all coding categories used to test moderators or mediators of } \\
\text { the relation(s) of interest. }\end{array}$ & Page 9 \\
\hline \multirow[t]{15}{*}{ Search Strategies } & 1. Reference and citation of databases searched & Page 8 \\
\hline & 2. $\quad$ Registries (including prospective registries) searched & Page 8 \\
\hline & a. Keywords used to enter databases and registries & Page 8 \\
\hline & b. Search software used and version & Page 10 \\
\hline & 3. Time period in which studies needed to be conducted if applicable & Page 8 \\
\hline & 4. $\quad$ Other efforts to retrieve all available studies & Page 8 \\
\hline & a. $\quad$ Listservs & N/A \\
\hline & b. Contacts made with authors (and how many authors were selected). & N/A \\
\hline & c. $\quad$ Reference lists of reports examined & Page 13 \\
\hline & 5. Methods of addressing reports in languages other than English & Page 8 \\
\hline & 6. $\quad$ Process for determining study eligibility & Page 8 \\
\hline & 7. Aspects of reports examined (i.e., title, abstract, and/or full text) & Page 8 \\
\hline & a. $\quad$ Number and qualifications or relevance judges & Page 15 \\
\hline & b. Indication of agreement & Page 15 \\
\hline & c. How disagreements were resolved & Page 15 \\
\hline
\end{tabular}




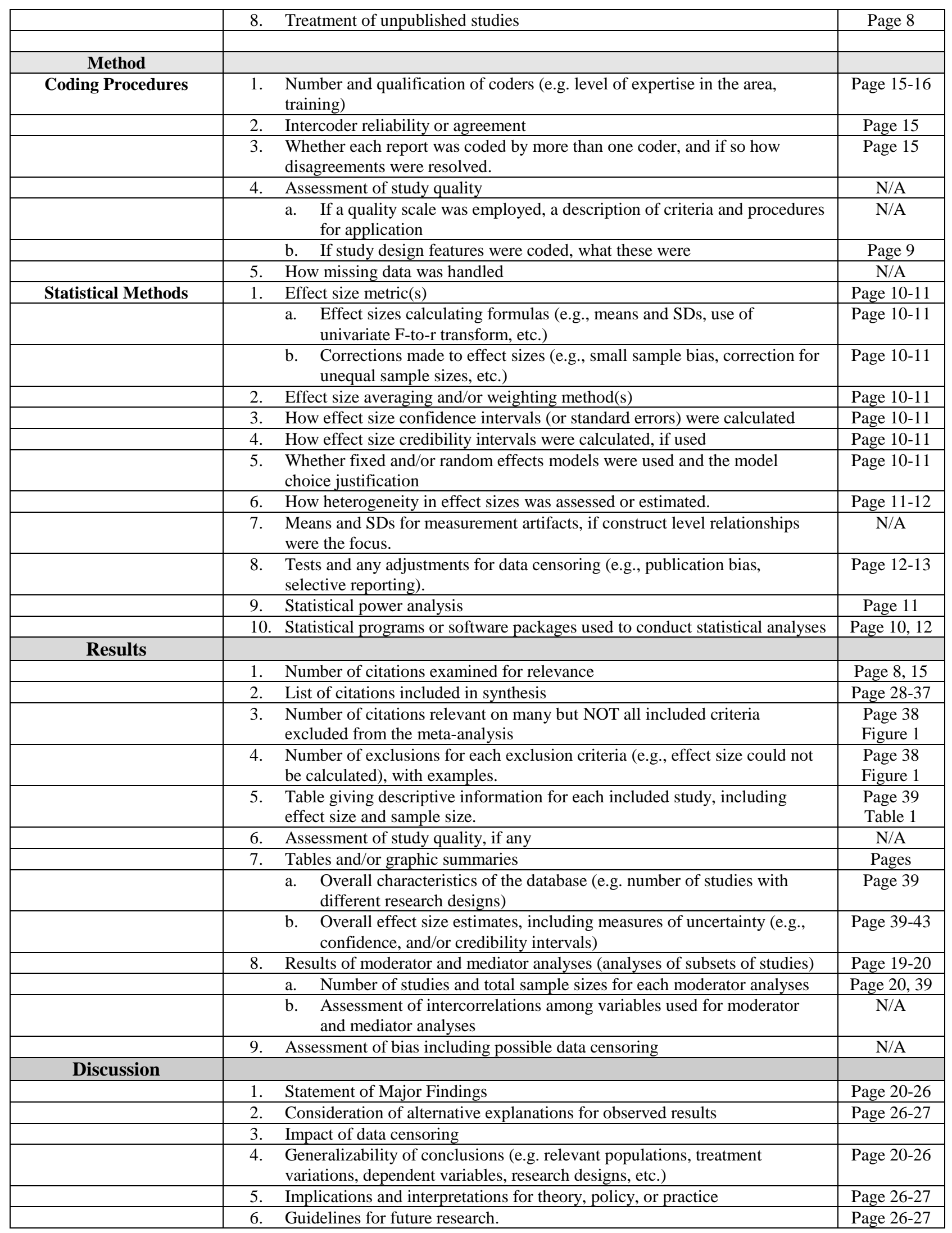


Table 1

Study Characteristics Meeting Inclusion Criteria.

\begin{tabular}{|c|c|c|c|c|c|c|c|c|c|c|c|c|c|}
\hline \multirow[b]{2}{*}{ Study } & \multicolumn{6}{|c|}{ Intervention Characteristics } & \multicolumn{4}{|c|}{ Participant Characteristics } & \multicolumn{3}{|c|}{$\underline{\text { Study Characteristics }}$} \\
\hline & Training & $\begin{array}{l}\text { Duration } \\
\text { (Weeks) }\end{array}$ & $\begin{array}{l}\text { Follow- } \\
\text { up }\end{array}$ & TARGET & $\begin{array}{c}\text { Manipulation } \\
\text { Check }\end{array}$ & Intensity & $N$ & $\begin{array}{c}\text { Age } \\
\text { (Years) }\end{array}$ & Level & Country & Type & $\begin{array}{l}\text { Outcome } \\
\text { Measure }\end{array}$ & $\begin{array}{c}\text { Effect } \\
(\mathrm{g})\end{array}$ \\
\hline Barkoukis et al., 2008 & $\mathrm{R}$ & 28 & No & Full & Yes & $\mathrm{R}$ & 374 & 13.8 & MS & Greece & $\mathrm{P}$ & 1 & 0.07 \\
\hline Boone, 1995 & $\mathrm{R}$ & 3 & No & Full & Yes & $\mathrm{R}$ & 268 & NR & MS & US & $\mathrm{U}$ & 2 & 0.24 \\
\hline Bowler et al., 2009 & $\mathrm{R}$ & 2 & No & Full & Yes & $\mathrm{R}$ & 32 & 13.5 & MS & UK & $\mathrm{U}$ & 2 & 0.50 \\
\hline Cecchini et al., 2001 & NR & 4 & No & Full & No & $\mathrm{R}$ & 115 & 11.7 & MS & Spain & $\mathrm{P}$ & 1 & -0.08 \\
\hline Christodoulis et al., 2001 & $\mathrm{R}$ & 40 & Yes & Partial & Yes & $\mathrm{R}$ & 634 & 15.0 & HS & Greece & $\mathrm{P}$ & 1 & 0.11 \\
\hline Cramer, 2000 & $\mathrm{R}$ & 12 & No & Full & Yes & $\mathrm{R}$ & 65 & 15.0 & HS & US & $\mathrm{U}$ & 2 & 0.19 \\
\hline Digelidis et al., 2003 & $\mathrm{R}$ & 40 & Yes & Full & Yes & $\mathrm{R}$ & 782 & 12.0 & MS & Greece & $\mathrm{P}$ & 1 & 0.24 \\
\hline Jakkola et al., 2006 & $\mathrm{R}$ & 40 & No & Full & No & $\mathrm{R}$ & 333 & 15.0 & HS & Finland & $\mathrm{P}$ & 1 & -0.01 \\
\hline Martin, et al., 2009 & $\mathrm{R}$ & 6 & No & Full & Yes & $\mathrm{R}$ & 64 & 5.58 & $\mathrm{E}$ & US & $\mathrm{P}$ & 2 & 0.46 \\
\hline Morgan et al., 2002 & $\mathrm{R}$ & 7 & No & Full & Yes & $\mathrm{R}$ & 153 & 13.6 & MS & UK & $\mathrm{P}$ & 1 & 0.03 \\
\hline Morgan et al., 2005 & $\mathrm{R}$ & 4 & No & Full & Yes & $\mathrm{R}$ & 92 & 12.9 & MS & UK & $\mathrm{P}$ & 2 & 0.00 \\
\hline Morgan et al., 2008 & $\mathrm{R}$ & 3 & No & Full & Yes & $\mathrm{R}$ & 80 & 13.7 & MS & UK & $\mathrm{P}$ & 2 & 0.14 \\
\hline Papaioannou et al., 1999 & $\mathrm{R}$ & 2 & No & Partial & Yes & $\mathrm{R}$ & 239 & 13.0 & MS & Greece & $\mathrm{P}$ & 1 & -0.10 \\
\hline Papaioannou et al., 2007a & NR & 1 & No & Partial & Yes & NR & 580 & 12.5 & MS & Greece & $\mathrm{P}$ & 1 & -0.12 \\
\hline Papaioannou et al., 2007b & NR & 1 & No & Partial & Yes & $\mathrm{R}$ & 351 & 13.0 & MS & Greece & $\mathrm{P}$ & 1 & 0.12 \\
\hline Solmon, 1996 & $\mathrm{R}$ & 1 & No & Partial & Yes & $\mathrm{R}$ & 109 & NR & MS & US & $\mathrm{P}$ & 2 & -0.01 \\
\hline Todorovich, et al., 2002 & NR & 2 & No & Full & Yes & $\mathrm{R}$ & 72 & 11.0 & $\mathrm{E}$ & US & $\mathrm{P}$ & 1 & 0.28 \\
\hline Todorovich et al., 2003 & NR & 2 & No & Full & Yes & $\mathrm{R}$ & 80 & NR & $\mathrm{E}$ & US & $\mathrm{P}$ & 1 & 0.06 \\
\hline Valentini et al., 2004a & $\mathrm{R}$ & 12 & Yes & Full & Yes & $\mathrm{R}$ & 39 & 5.43 & $\mathrm{E}$ & US & $\mathrm{P}$ & 2 & 0.59 \\
\hline Valentini et al., 2004a & $\mathrm{R}$ & 12 & Yes & Full & Yes & $\mathrm{R}$ & 56 & 5.10 & $\mathrm{E}$ & US & $\mathrm{P}$ & 2 & .0 .56 \\
\hline Valentini et al., 2004b & $\mathrm{R}$ & 12 & No & Full & No & $\mathrm{R}$ & 104 & 7.80 & $\mathrm{E}$ & Brazil & $\mathrm{P}$ & 2 & 0.56 \\
\hline Viciana et al., 2007 & $\mathrm{R}$ & 7 & No & Partial & Yes & $\mathrm{R}$ & 95 & 15.0 & HS & Spain & $\mathrm{P}$ & 1 & -0.10 \\
\hline Wallhead et al., 2004 & NR & 8 & No & Partial & Yes & $\mathrm{R}$ & 51 & 14.3 & MS & UK & $\mathrm{P}$ & 2 & 0.39 \\
\hline Weigand et al., 2002 & NR & 5 & No & Full & No & $\mathrm{R}$ & 40 & 15.9 & HS & UK & $\mathrm{P}$ & 1 & 0.44 \\
\hline
\end{tabular}

Note. Training: R=Reported; NR=Not Reported. Duration (Weeks): NR=Not Reported. Intensity: R= Reported; NR= Not Reported. Level: E= Elementary; MS=Middle School; HS=High School. Type: P=Published; U=Unpublished. Outcome Measures: 1=Self-Report; 2= Combination (Self-Report and Objective Measure). The effect size reported for study characteristics is a summary effect across all outcome variables per study. 
Table 2

Outcome Analysis

\begin{tabular}{|c|c|c|c|c|c|c|c|c|c|c|}
\hline \multirow[b]{2}{*}{ VARIABLE } & \multicolumn{5}{|c|}{ Effect Size Statistics } & \multirow{2}{*}{$\frac{\text { Null Test }}{Z}$} & \multicolumn{3}{|c|}{ Heterogeneity Statistics } & \multirow{2}{*}{$\frac{\text { Publication Bias }}{\text { Fail Safe } N}$} \\
\hline & $k$ & $g$ & $S E$ & $s^{2}$ & $95 \%$ C.I. & & $Q$ & $\tau^{2}$ & $I^{2}$ & \\
\hline \multicolumn{11}{|l|}{ Affective Outcomes } \\
\hline Attitude & 4 & 0.599 & 0.238 & 0.057 & $.133,1.07)$ & $2.518 *$ & $48.311 *$ & 0.205 & 93.79 & 125 \\
\hline Boredom & 3 & -0.274 & 0.268 & 0.072 & $-.801, .252)$ & -1.022 & $8.665^{*}$ & 0.162 & 76.92 & 1 \\
\hline Enjoyment & 11 & 0.149 & 0.054 & 0.003 & $.043, .255)$ & $2.750 *$ & $22.64 *$ & 0.015 & 55.83 & 45 \\
\hline \multicolumn{11}{|l|}{ Behavioural Outcomes } \\
\hline Health/Fitness & 4 & 0.492 & 0.110 & 0.012 & $.277, .706)$ & $4.486^{*}$ & 6.365 & 0.022 & 52.87 & 52 \\
\hline Skills & 7 & 0.395 & 0.107 & 0.011 & $.185, .605)$ & $3.692 *$ & 9.510 & 0.028 & 36.91 & 35 \\
\hline \multicolumn{11}{|l|}{ Cognitive Outcomes } \\
\hline Anxiety & 3 & -0.246 & 0.072 & 0.005 & $.387,-.104)$ & $-3.406^{*}$ & 2.970 & 0.005 & 28.324 & 10 \\
\hline Commitment & 3 & 0.183 & 0.122 & 0.015 & $-.055, .422)$ & 1.508 & 5.515 & 0.026 & 63.74 & 4 \\
\hline Competence/Confidence & 9 & 0.118 & 0.133 & 0.018 & $-.143, .378)$ & 0.883 & $75.61 *$ & 0.121 & 89.42 & 3 \\
\hline Competitive Strategies & 4 & -0.074 & 0.073 & 0.005 & $-.216, .069)$ & -1.016 & 6.639 & 0.011 & 54.81 & 0 \\
\hline Learning Strategies & 3 & 0.285 & 0.084 & 0.007 & $.121, .448)$ & $3.409 *$ & 2.154 & 0.002 & 7.147 & 5 \\
\hline Ego Orientation & 14 & -0.065 & 0.078 & 0.006 & $-.217, .087)$ & -0.834 & $63.93 *$ & 0.057 & 79.67 & 12 \\
\hline Task Orientation & 14 & 0.181 & 0.057 & 0.003 & $.069, .292)$ & $3.172 *$ & $44.46^{*}$ & 0.027 & 70.76 & 114 \\
\hline Mastery Climate & 13 & 0.318 & 0.053 & 0.003 & $.215, .422)$ & $6.006^{*}$ & $34.28 *$ & 0.020 & 64.99 & 224 \\
\hline Performance Climate & 12 & -0.239 & 0.102 & 0.010 & $.438,-.039)$ & $-2.344 *$ & $78.63^{*}$ & 0.093 & 86.01 & 110 \\
\hline Perceptions of Ability & 6 & 0.078 & 0.163 & 0.027 & $-.242, .398)$ & 0.479 & $36.88^{*}$ & 0.123 & 86.44 & 0 \\
\hline Perceptions of Effort & 5 & 0.082 & 0.051 & 0.003 & $-.018, .182)$ & 1.608 & 2.525 & 0.000 & 0.000 & 0 \\
\hline
\end{tabular}

Note. $k=$ number of effect sizes. $g=$ Effect size (Hedges $g$ ). $S E=$ Standard Error. $\mathrm{S} 2=$ variance. $95 \%$ C.I.= Confidence Intervals (lower limit, upper limit). Z $=$ test of the null hypothesis. $\tau^{2}=$ Between study variance in Random Effects Model. $I^{2}=$ Total variance explained by moderators. $*$ indicates a significant $\mathrm{Q}_{\text {Total }}$ value, $\mathrm{p} \leq .05$. 
Table 3

Intervention Moderator Statistics

\begin{tabular}{|c|c|c|c|c|c|c|c|c|c|}
\hline & \multicolumn{5}{|c|}{ Effect Size Descriptive Statistics } & \multirow{2}{*}{$\frac{\text { Null Test }}{Z}$} & \multicolumn{3}{|c|}{ Heterogeneity Statistics } \\
\hline & $k$ & $g$ & $S E$ & $s^{2}$ & $95 \%$ C.I. & & $Q$ & $\tau^{2}$ & $I^{2}$ \\
\hline Random Effects Model ${ }^{\mathrm{A}}$ & 24 & 0.103 & 0.035 & 0.001 & $(.034, .171)$ & $2.922 *$ & $38.59^{*}$ & 0.009 & 40.40 \\
\hline Intervention Features ${ }^{\mathrm{B}}$ & & & & & & & & & \\
\hline Training & & & & & & & $0.083^{\mathrm{B}}$ & & \\
\hline Reported & 17 & 0.087 & 0.075 & 0.006 & $(.029, .195)$ & $2.639 *$ & & 0.007 & 47.66 \\
\hline Not Reported & 7 & 0.112 & 0.042 & 0.002 & $(-.059, .234)$ & 1.169 & & 0.013 & 24.74 \\
\hline Time Period & & & & & & & $3.197^{\mathrm{B}}$ & & \\
\hline$<3$ weeks & 7 & 0.023 & 0.061 & 0.004 & $(-.097, .142)$ & 0.375 & & 0.012 & 50.13 \\
\hline 3-8 weeks & 10 & 0.106 & 0.057 & 0.003 & $(-.006, .219)$ & 1.852 & & 0.000 & 0.000 \\
\hline$>8$ weeks & 7 & 0.178 & 0.062 & 0.004 & $(.057, .300)$ & $2.869 *$ & & 0.016 & 51.22 \\
\hline Follow-up & & & & & & & $3.410^{\mathrm{B}}$ & & \\
\hline No & 20 & 0.072 & 0.036 & 0.001 & $(.002, .142)$ & $2.028^{*}$ & & 0.007 & 33.69 \\
\hline Yes & 4 & 0.231 & 0.081 & 0.007 & $(.071, .390)$ & $2.838 *$ & & 0.005 & 17.96 \\
\hline TARGET & & & & & & & $3.608^{\mathrm{B}}$ & & \\
\hline Full & 17 & 0.150 & 0.043 & 0.002 & $(.066, .234)$ & $3.500 *$ & & 0.007 & 29.54 \\
\hline Partial & 7 & 0.016 & 0.056 & 0.003 & $(-.093, .126)$ & 0.289 & & 0.014 & 47.23 \\
\hline Manipulation Check & & & & & & & $1.822^{\mathrm{B}}$ & & \\
\hline No & 5 & 0.165 & 0.099 & 0.010 & $(-.029, .359)$ & $1.664 *$ & & 0.026 & 48.65 \\
\hline Yes & 19 & 0.095 & 0.039 & 0.001 & $(.002, .148)$ & $2.462 *$ & & 0.006 & 33.24 \\
\hline
\end{tabular}

Note. A=Total Q-value used to determine heterogeneity; B=Between Q-value used to determine significant differences ( $\alpha=.01)$ between moderators. $k=$ number of effect sizes. $g=$ Effect size (Hedges $g$ ). $S E=$ Standard Error. S2 = variance. 95\% C.I.= Confidence Intervals (lower limit, upper limit). Z $=$ test of the null hypothesis. $\tau^{2}=$ Between study variance in Random Effects Model. $I^{2}=$ Total variance explained by moderators. $* \mathrm{p} \leq .05$. 
Table 4

Participant and Study Moderator Statistics

\begin{tabular}{|c|c|c|c|c|c|c|c|c|c|}
\hline \multirow{3}{*}{ Random Effects Model ${ }^{\mathrm{A}}$} & \multicolumn{5}{|c|}{ Effect Size Descriptive Statistics } & \multirow{2}{*}{$\frac{\text { Null Test }}{Z}$} & \multicolumn{3}{|c|}{ Heterogeneity Statistics } \\
\hline & $k$ & $g$ & $S E$ & $s^{2}$ & $95 \%$ C.I. & & $Q$ & $\tau^{2}$ & $I^{2}$ \\
\hline & 24 & 0.103 & 0.035 & 0.001 & $(.034, .171)$ & $2.922 *$ & $38.59 *$ & 0.009 & 40.40 \\
\hline \multicolumn{10}{|l|}{ Participant Features $^{\mathrm{B}}$} \\
\hline Level & & & & & & & $8.840^{\mathrm{B}}$ & & \\
\hline Elementary School & 6 & 0.407 & 0.105 & 0.012 & $(.192, .622)$ & $3.710 *$ & & 0.000 & 0.000 \\
\hline Middle School & 12 & 0.068 & 0.060 & 0.001 & $(-.002, .138)$ & 0.940 & & 0.009 & 50.75 \\
\hline High School & 6 & 0.066 & 0.026 & 0.005 & $(-.071, .203)$ & 1.896 & & 0.000 & 0.000 \\
\hline Country & & & & & & & $10.19^{\mathrm{B}}$ & & \\
\hline Brazil & 1 & 0.563 & 0.216 & 0.047 & $(.140, .986)$ & $2.610 *$ & & 0.000 & 0.000 \\
\hline Finland & 1 & -0.005 & 0.126 & 0.016 & $(-.252, .242)$ & -0.039 & & 0.000 & 0.000 \\
\hline Greece & 6 & 0.058 & 0.047 & 0.002 & $(-.034, .150)$ & 1.238 & & 0.013 & 68.30 \\
\hline Spain & 2 & -0.084 & 0.176 & 0.031 & $(-.429, .260)$ & -0.480 & & 0.000 & 0.000 \\
\hline United Kingdom & 6 & 0.089 & 0.065 & 0.004 & $(-.038, .215)$ & 1.378 & & 0.002 & 9.835 \\
\hline United States & 8 & 0.239 & 0.081 & 0.007 & $(.081, .397)$ & $2.962 *$ & & 0.000 & 0.000 \\
\hline \multicolumn{10}{|l|}{ Study Features ${ }^{B}$} \\
\hline Type & & & & & & & $1.794^{\mathrm{B}}$ & & \\
\hline Published & 21 & 0.087 & 0.036 & 0.001 & $(.017, .157)$ & $2.423^{*}$ & & 0.020 & 42.92 \\
\hline Unpublished & 3 & 0.251 & 0.117 & 0.014 & $(.022, .479)$ & $2.145^{*}$ & & 0.000 & 0.000 \\
\hline Outcome Measure & & & & & & & $3.242^{\mathrm{B}}$ & & \\
\hline Combination & 12 & 0.189 & 0.060 & 0.004 & $(.072, .307)$ & $3.169 *$ & & 0.015 & 34.35 \\
\hline Self-Report & 12 & 0.057 & 0.043 & 0.002 & $(-.027, .141)$ & 1.338 & & 0.007 & 42.64 \\
\hline
\end{tabular}

Note. ${ }^{*} \mathrm{p} \leq .05 . \mathrm{A}=$ Total Q-value used to determine heterogeneity; B=Between Q-value used to determine significant moderator differences. Please refer to Table 3 footnotes for explanations regarding column headings. 


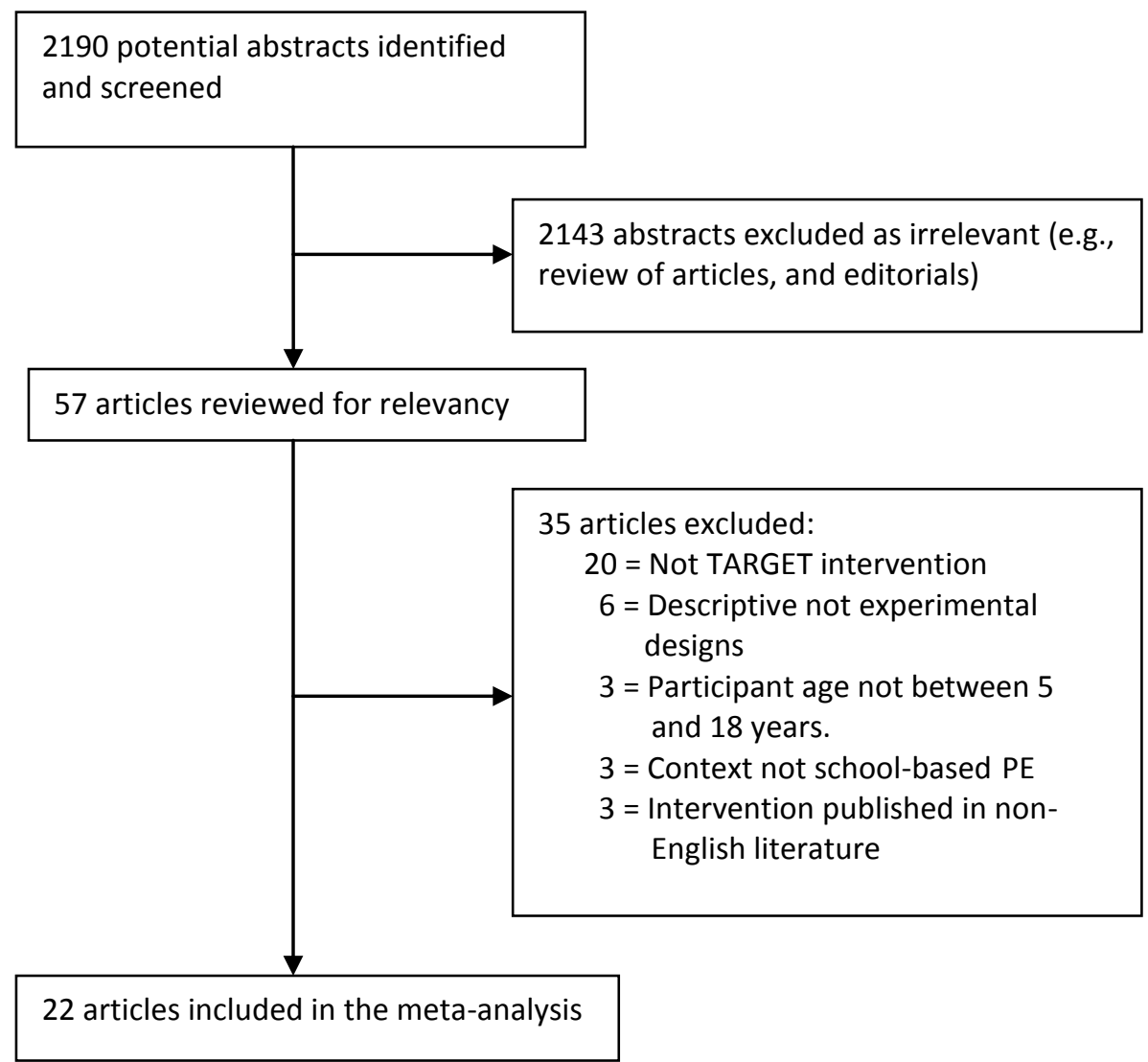

Figure 1. Selection of TARGET framework intervention manuscripts within physical education contexts. 